Article

\title{
Motion and Dynamic Responses Approach for WindFloat Structures under Marine Loads
}

\author{
I C Scurtu', D Gârleanu², G Gârleanu² \\ 1 Naval Academy “Mircea cel Batran", Constanta, Romania; \\ 2 University Politehnica of Bucharest, Bucharest, Romania; \\ * Correspondence: delia.garleanu@upb.ro; Tel.: +04-0770-270-545
}

Abstract: This paper presents performed Ansys numerical simulation on WindFloat structures. It contributes to the methodology of movements calculation based on CFD instruments. The movements of the semi-submersible structures in waves are difficult to compute in numerical simulation and this highlights the importance of using RAO functions. RAO numerical approach developed can be applied to design semisubmersible WindFloat structures in order to fulfill essential requirements regarding operational safety and design. Numerical methodology was designed in accordance marine loads and the I.T.T.C. recommendations. The numerical RAO results for regular wave movements include many elements for the semi-submersible structure. Close results to open sea operation can be achieved by constant improvement in numerical simulation methodologies.

The work opens the way for further hydrodynamic development on irregular waves for realistic hydrodynamic and structural response of the actual semi-submersibles at sea. The results demonstrate the accuracy of RAO function approach for specific WindFloat in Jonswap spectrum.

Keywords: wave energy, marine loads, RAO function, dynamic response

\section{Introduction}

Increasing global oil consumption of petroleum products and derivatives leads to the development of petroleum extraction companies. The development of new offshore technology is of particular interest due to the high demand of the market. These structures make it possible to exploit the oil and gas fields in increasingly deep depths [1,2].Thus, offshore structures operate in the marine environment and are exposed to various environmental demands and operational loads for which they are carried out. Current, wave, and wind generate dynamic responses to structures of a rather high complexity, given the plurality of installations and equipment on board platforms.[3-8] The marine environment has a pronounced dynamic action and this requires a careful analysis (using RAO functions) of how the energy of the specified components is transferred to marine structures. Structures like WindFloat have reduced vertical movements in waves [8,9].

Waves and currents loads are the most important in the class of loads due to the marine environment when it comes to offshore structures. The forces that occur at the level of the structure are caused by water movement due to waves and currents. In order to determine these loads, it is necessary to idealize the wave's surface and wave's cinematic wave theory. The centuries-old waveform data is used and there is no dynamic reaction to the structure being considered. The static calculation is more than enough if the dominant waves have a much longer period than the studied structure.

Marine structure design is a complex process designed to ensure hydrodynamic and structural performance requested by the customer, in direct correlation with the qualities of reliability and maintenance throughout the marine operating system. Hydrodynamic risk assessment, estimating indicators of structural safety and the prevention of structural failure are possible only after studying the system behavior under the influence of environmental factors and determining its sea keeping performance with RAO values specific to each structure. 
WindFloat systems are used to capture wind energy and produce electricity without polluting the environment. To improve the overall quality of the marine system design, there is a need to investigate the issue of Wind Float type structure movement on the incidental waves. The solution of the problem set of operating conditions depends on the sea, and the anchor lines forces of the floating marine system. Using overlapping effects hypothesis in Jonswap, movements are assessed and computed for non-restricted floating object. Anchor lines are not considered in the motion analysis. This paper refers only to solve the problem of the WindFloat without ties.

Hydrodynamic performance of WindFloat depends essentially on the knowledge of forces and hydrodynamic moments acting on real sea. Estimating structural system response in marine incident waves depends on the complexity and depth of the modeling of hydrodynamic analysis. In the event of overlapping effects, hydrodynamic forces acting on the body are obtained by solving diffraction and radiation in Ansys.

In the situation of stationary marine structures composed of bodies with significant volumes, hydrodynamic forces generated by wave's action are determined by solving the problem of diffraction. Froude-Krilov component can be determined by assuming unaltered incident wave and the diffraction component, taking into account the free surface deformation in the presence of semisubmersible body. The problem of radiation is generated by oscillations movements of the semisubmersible structure with six degrees of freedom in the fluid, which is initially at rest and allows the identification of the radiation, which characterizes the hydrodynamic and hydrostatic body through additional masses matrices of potential amortization coefficients and hydrostatic coefficients.

The structure was placed symmetrically in the forward direction of the waves. There has been studied the structural semi-submersible behavior in regular stern waves according to RAO presented theory. Numerical determination of heave (first order movement) of a WindFloat system on longitudinal waves (in the absence of anchor lines) is the main objective of this paper.

\section{Theory and numerical methods}

\subsection{Jonswapspectrum theory}

Hasselmann analyzed the data collected in the Jonswap North Sea Wave Observation Project where he found that the spectrum of the wave was never fully developed. It continues to develop through non-linear wave-valves even for a long period of time and long distances. Therefore, an additional and to a certain extent artificial factor was added to the Pierson-Moskowitz spectrum to improve compatibility with their measurements[10-15].The Jonswap spectrum is thus a PiersonMoskowitz spectrum multiplied by an additional peak factor $\gamma^{\text {r: }}$

$$
S_{j}(\omega)=\frac{\alpha g^{2}}{\omega^{5}}\left[-\frac{5}{4}\left(\frac{\omega_{p}}{\omega}\right)^{4}\right] \gamma^{\Gamma}
$$

where :

$$
\Gamma=\exp \left[-\frac{\left(\omega-\omega_{p}\right)^{2}}{2 \sigma^{2} \omega_{p}^{2}}\right] .
$$




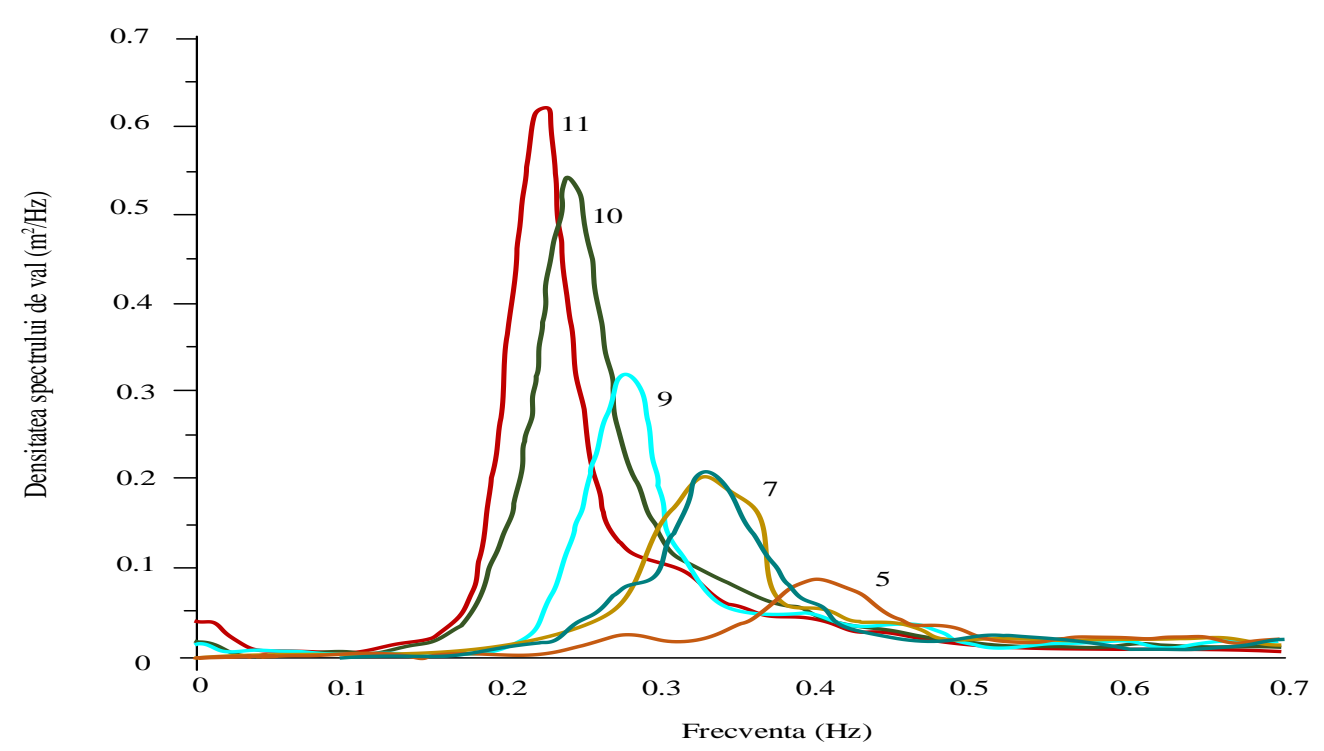

Figure 1. Spectrum of the wave to great development for different situations

Figure 1 shows the spectrum of the wave using the Hasselmann and Colb measurements. In 1973 and Figure 2, we present a comparison of the Jonswapand Pierson-Moskowitz spectra.

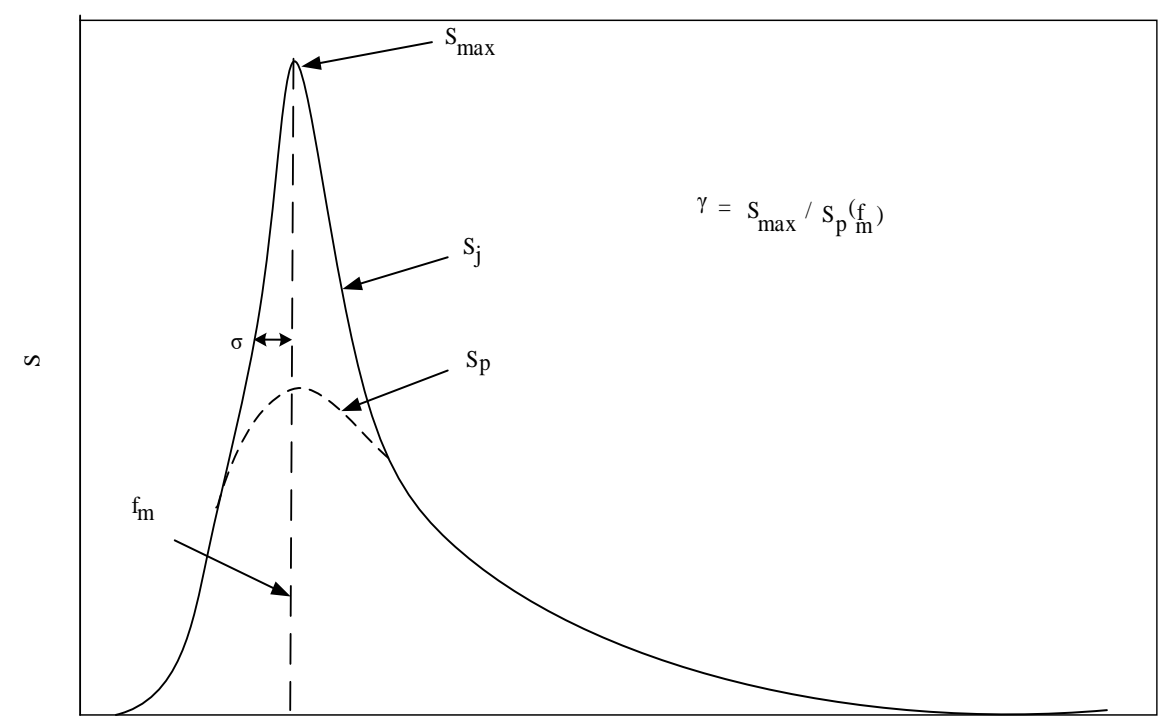

Figure 2.JonswapSpectrum and Pierson-Moskowitz Spectrum

Wave data collected during the Jonswap experiment was used to determine the values for the constants in the equations below[16-20]:

$$
\begin{gathered}
\alpha=0.076\left(\frac{U_{10}{ }^{2}}{F g}\right)^{0.22} \\
\omega_{p=22\left(\frac{g^{2}}{U_{10 F}}\right)^{1 / 3}} \quad \gamma=3.3 \\
\sigma=\left\{\begin{array}{l}
0.07 \omega \leq \omega_{p} \\
0.09 \omega \geq \omega_{p}
\end{array}\right.
\end{gathered}
$$

Where $\mathrm{F}$ is the distance to a shore, or the distance the wind blows at constant speed.

The wave energy increases with the distance to the shore: $\left\langle\zeta^{2}\right\rangle=1.67 \times 10^{-7} \frac{\left(\mathrm{U}_{10}\right)^{2}}{\mathrm{~g}} \mathrm{~F}$ 
The Jonswap spectrum is similar to the Pierson-Moskowitz spectrum except that the waves continue to increase with the distance (or time) specified by a term, and the peak in the spectrum is more pronounced, as specified by the term g.[21, 22] This latter proves to be is particularly important because it leads to the reinforcement of nonlinear interactions and a spectrum that changes over time according to the Hasselmann's 1966 theory.

There are many variables for the structure presented in this paper: loads differ, way of anchoring at that point differs and mode of operation and the equipment used on board is very different, so I consider this area to be of particular complexity and due to current developments in field. $[23,24]$ The report will present RAO calculation mode for any structure offshore and will identify the possible loads for using RAO in dedicated engineering software to determine movements of the analyzed structures.

\subsection{WindFloat structure geometry}

The semi-submersible structure to be analyzed is made up of three vertical cylindrical columns, with a height of $20 \mathrm{~m}$ and a diameter of $10 \mathrm{~m}$, connected by cylindrical bars cross-systems mounted in V. Semi-submersible structure's draft is $16 \mathrm{~m}$ and weight is 3500 t.In Figure 3, we present the semisubmersible platform from WindFloat project designed with DesignModeller in ANSYS Workbench [25-30]. Model presented is imported in Ansys for vertical motion (heave) approach in waves.

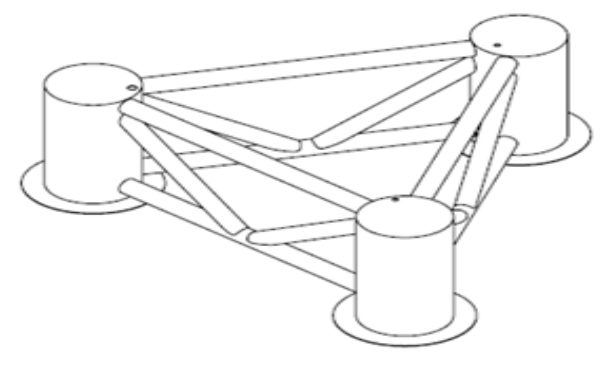

Figure 3. Geometry for WindFloat floating structure

Resonance phenomena for offshore structures are strictly forbidden for the safe operation and proper operation of onboard systems. Knowing that the sea waves have a period of between 14 and 20 seconds, it is logically deduced why fixed structures generally have low oscillation periods ( 2.5 seconds), and platforms that use positive buoyancy to sit on the water surfacewill have a period of about 300 seconds[31-34].

\subsection{Ansys geometry in Design Modeler}

Knowing the static and dynamic response of the structure depends a lot on the physical or mathematical models of the initial working hypotheses, which leads to differences between the different methods of calculating the interactions of the marine environment with the offshore structures[35]. Ansys analysis in structure dynamics is a delicate subject taking into account the 
complexity of the phenomena studied for high mass floating structure with properties presented in table 1.Wave analysis will use wave with amplitude $\mathrm{Hs}=1.2 \mathrm{~m}$ for simulation time of 3600sec.

Table 1. Geometry Properties

\begin{tabular}{|r|c|}
\hline Mass Definition & Manual Definition \\
\hline Mass & $3500000 \mathrm{~kg}$ \\
\hline Inertia Properties \\
\hline Define Inertia Values By & Radius of Gyration \\
\hline Kzz & $27 \mathrm{~m}$ \\
\hline Ixx & $4287500000 \mathrm{~kg} \cdot \mathrm{m}^{2}$ \\
\hline Iyy & $4287500000 \mathrm{~kg} \cdot \mathrm{m}^{2}$ \\
\hline Izz & $2551500000 \mathrm{~kg} \cdot \mathrm{m}^{2}$ \\
\hline
\end{tabular}

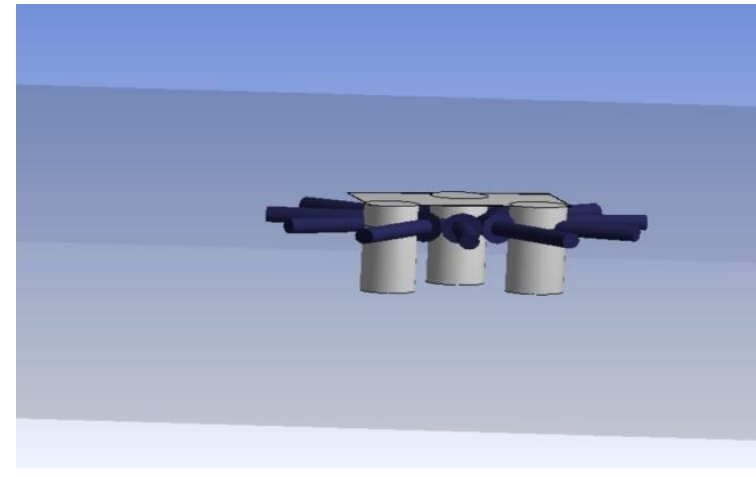

Figure 4. Floating structure in 3D

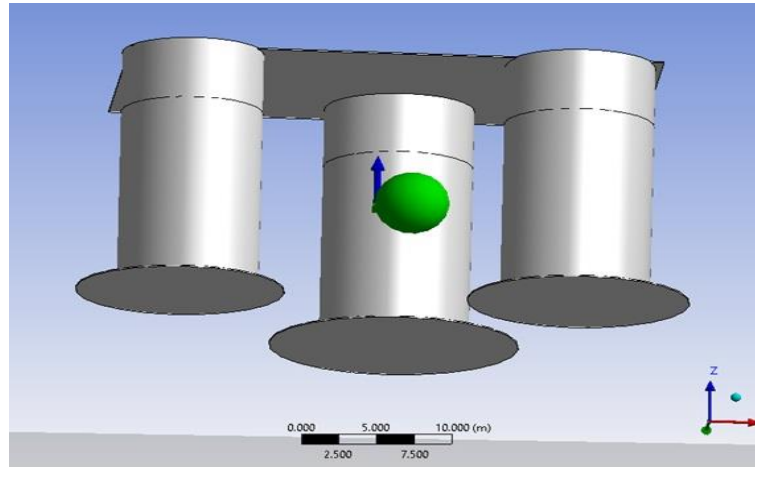

Figure 5. Floating structure with heave plates(HP)

Specific to this work is the synthesis of information of interest in the field of dynamic interactions between offshore structures and the marine environment, with hydrodynamic components being highlighted. The model currently used in the RAO evaluation with ANSYS software is shown in Figures4 and 5.

\section{Offshore structures specific marine loads}

During the exploitation period, a structure is in continuous interaction with the marine environment therefore the design of offshore structures takes into account the following types of loads [35]:

$>$ Loads due to continuous interaction with the marine environment.

$>$ Dead loads are due to the weight of the structure in the air plus the weight of the ballast, the masses of the equipment permanently mounted on the platform, the buoyancy and the hydrostatic forces on the immersed parts.

$>$ Live loads are due to the masses of equipment and materials that are not permanently on board and the forces generated during the operation of the equipment. Loads due to operation include living spaces, consumables, liquids, life-maintenance systems, furniture and heliports. For example: crane operation, helicopter landing. According to the British Standards BS6235, the following are recommended for calculation: Crew spaces and passages $3,2 \mathrm{KN} / \mathrm{m} 2$ and for working spaces $8,5 \mathrm{KN} / \mathrm{m}^{2}$ 
$>$ Environmental loads are: wind, wave, temperature, snow and ice, marine organisms and earthquakes.

\subsection{Marine waves and currents loads}

The design of offshore structures is dominated by the loads due to the marine environment and, in particular, wave loads [36]. The wind loads act on the surface of the structures, equipment on board and are distributed over the surface projected on a plane transverse to the direction of the wind. For the most unfavorable wave and wind combinations according to the literature, one of the two is chosen: 1 minute continuous wind combined with extreme waves or 3 gusts with maximum intensity. For higher heights of structures, standards require that the dynamic effects of wind loads be taken into account as the whirling whirlwinds need to be investigated.

This is the case with structures in deep water subject to extreme storms. Waves are characterized by the following parameters: wave height $(\mathrm{H})$, period $(\mathrm{T})$, water depth $(\mathrm{d})$.

Wave theory describes the kinematics of water waves. They serve to calculate the particle velocities, their accelerations and dynamic pressure as a function of the wave height.

Structures exposed to wave action are required by forces much higher than in the wind. [38] The forces result from dynamic pressure and motion of water particles. Two cases can be distinguished.

1. Large volume bodies that influence wave structure by diffraction and reflection phenomena. These forces can be calculated using the diffraction theory.

2. Thin, transparent hydrodynamic bodies that have no influence on wave structure. These forces can be calculated using Morison's equation. Marine fixed offshore structures of tubular lattice are often assimilated to thin bodies. Morison's equation expresses force as an amount of inertial force proportional to particle acceleration and a nonlinear force of forward force proportional to the particle velocity square.

Snow and ice loads. Ice is the main problem in Arctic and Subarctic areas. Generating ice and expanding it can create a pressure high enough to cause problems both in the horizontal and the vertical direction. Large ice blocks driven by current, wind and waves can hit the structure at speeds of up to $1 \mathrm{~m} / \mathrm{s}$, leading to considerable impact loads [39].

Temperature loads. Differences in temperature can cause stress at the level of the structure. Therefore during the design period the extreme values to be encountered during the life cycle of the structure must be determined. The temperature of the crude oil and gas produced must also be taken into account.

$>$ Loads due to construction and installation.

$>$ Accidental loads. According to the registry specifications, these are loads that may result from an accident or exceptional circumstances.

Environmental loads should be considered according to the likelihood of meeting them in the operating area of the platform.

Ocean waves are composed of waves with different frequencies and directions. The waves from different directions interact and cause wave conditions to be very difficult to model mathematically. Below is the ABS proposed model for analyze loads. 


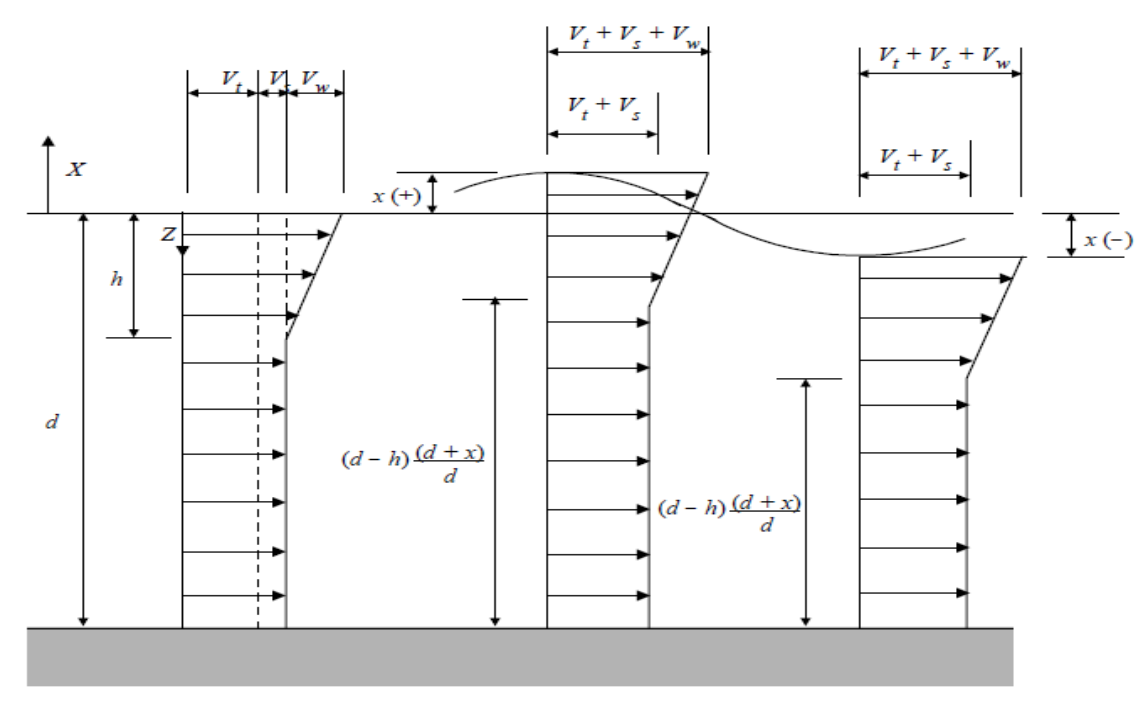

Figure 6. The ABS speed profile according to American Bureau of Shipping, Mobile offshore drilling units 2012

Hydrodynamic loading on a marine structure is mainly caused by the kinematics of water particles in waves, motions of the structure, and interactions between waves and the structure.

\subsection{Wind loads specific to the western part of the Black Sea basin}

The wind regime influences how crews can operate, thus influencing their activities, and brings additional loads to offshore structures that cannot be neglected at all.[40]In order to be able to analyze the dynamic behavior of an offshore structure, we need to know the hydro-meteorological conditions in the area where the offshore vessel or structure operates, because the forces and moments induced in dynamic calculations depend in particular on the large area of the structure, high in offshore structures. For the western area of the Black Sea data obtained from the Institute of Meteorology and Hydrology, I.M.H. the following can be highlighted:

> Minimum wind speeds are around $4 \mathrm{~m} / \mathrm{s}$ (multiannual average) while maximum values have exceeded 45 m/s (storms from 7-11 Dec. 1991, 3-5 January 1995, 25-30 Dec. 1996, Dec. 15-18, 1998)

> Violent storms (sea level> 8) were registered only in the winter months, with higher values registered on 4 January 1995 and 8 Dec.1991, when wind speeds exceeded 47 m/s.

Table 2. The frequency distribution of the force determined by the Beaufort scale

\begin{tabular}{|l|c|c|c|c|}
\hline Wind force & 0.3 & $4 . .5$ & $6 . .7$ & $8 . .12$ \\
\hline Frequency \% & 37 & 48 & 12 & 3 \\
\hline
\end{tabular}




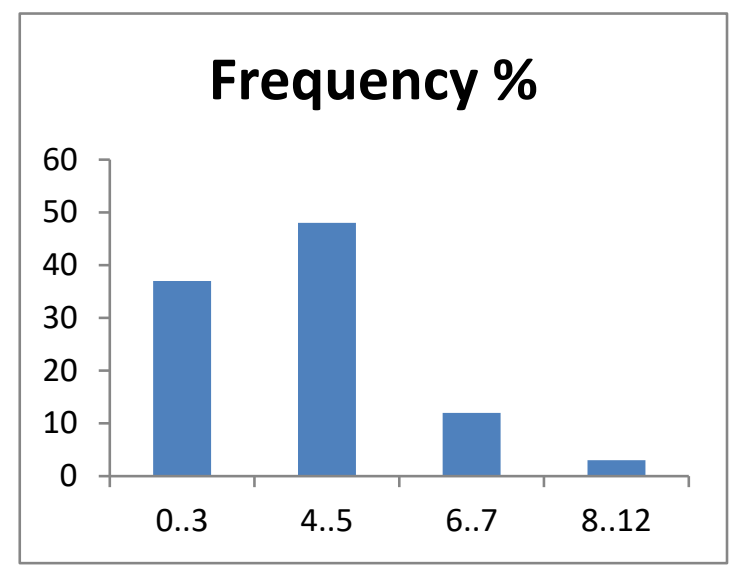

Figure 7. The frequency distribution of the force determined by the Beaufort scale

\section{Frecquency \%}

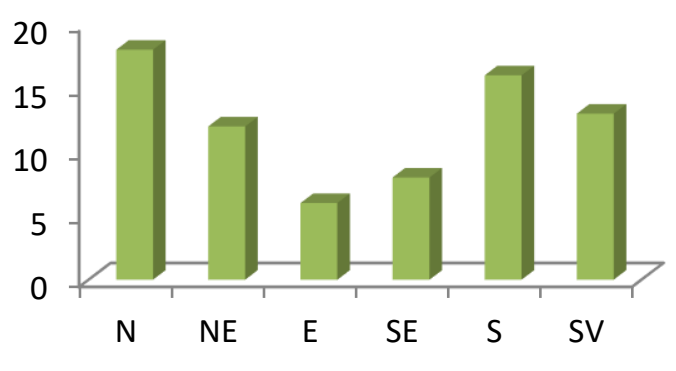

Figure 8. Distribution of Wind Direction

Frequency

From Figure 7 we can observe that the largest proportion of the wind direction is in the direction North and in Figure 8, it is noted that the most common winds are $85 \%$ of the $0-5$ grade winds on the Beaufort scale, and only $15 \%$ are winds of more than 6 on the Beaufort scale. However, for design, construction, the highest values of wind speeds should be chosen regardless of their frequency.

\section{Results as Response Amplitude Operators (RAO) values}

The hydrodynamic model allows the formulation of general equations of WindFloat motion type on regular waves, applying Newton's second law, being essentially a linear pattern that overlaps solutions of diffraction and radiation problems analyzed in the frequency domain. Assuming the side symmetry of the marine structure, the system of differential motion equations are reduced to two sets of equations: one set engages the translational motion in the longitudinal direction, with vertical and pitch ones, and the other links the movements of translation in a lateral direction, with the roll and the angular rotation around the vertical axis. In this paper, we analyzed the vertical motions of structure Wind Float assuming typical longitudinal waves.

Solving the system of differential equations of semi-submersible structure motion on regular waves allows both calculations of operators in amplitude response (RAO functions). RAO functions depend on the excitation frequency. At resonance, when the incident of wave's pulsation is equal to semi-submersible structure pulsation, the values record maximum value RAO functions.

Table no. 2 presents the values of operators' amplitude response $\mathrm{RAO}_{z}$ for vertical movements (heave) and angular movements (pitching) $\mathrm{RAO}_{\ominus}$ for semi-submersible structure without end plates, stationed in the regular stern waves. It is noted that these movements are negligible.

RAO functions are defined by relations:

$$
\begin{aligned}
& R A O_{z}=\left(\frac{z}{\zeta_{w}}\right)^{2} \\
& R A O_{\theta}=\left(\frac{\theta}{\zeta_{w}}\right)^{2}
\end{aligned}
$$


where, $\zeta_{w}$ is the regular longitudinal wave amplitude, $\mathrm{z}$ is the amplitude of semi-submersible

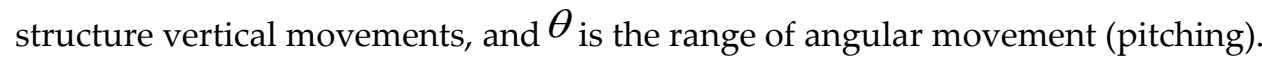

Table 3. RAO numerical functions on regular waves of stern ( $\alpha=0^{\circ}$ )

\begin{tabular}{|c|c|c|c|}
\hline $\begin{array}{c}\text { Test } \\
\text { No. }\end{array}$ & $f_{w}[\mathrm{~Hz}]$ & $\begin{array}{c}\text { Vertical } \\
\text { movements }\end{array}$ & $\begin{array}{c}\text { Angular } \\
\text { movements }\end{array}$ \\
\hline 1 & 0.072 & $0.355 \times 10^{-6}$ & 0.9012 \\
\hline 2 & 0.082 & $1.615 \times 10^{-6}$ & 25.514 \\
\hline 3 & 0.113 & $0.329 \times 10^{-6}$ & 0.322 \\
\hline 4 & 0.135 & $0.058 \times 10^{-6}$ & 0.1928 \\
\hline 5 & 0.146 & $0.247 \times 10^{-6}$ & 0.3036 \\
\hline
\end{tabular}

Table no.3 presents the values of $\mathrm{RAOz}$ and $\mathrm{RAO}_{\theta}$ operators, of semi-submersible structure without end plates, stationed in the regular bow waves. In this case, the vertical movements are insignificant. Angular movements of the plane of symmetry of the structure are lower than those calculated on the waves' stern.

For studying the influence of endplate there were analyzed only if stationing semi-submersible structure on the aft regular waves, characterized by angular significant. There is a significant reduction of angular movements' structure that uses endplates (Table 4).

Table4. RAO numerical functions on regular waves of stern with end plates $\left(\alpha=0^{\circ}\right)$

\begin{tabular}{|c|c|c|c|}
\hline $\begin{array}{c}\text { Test } \\
\text { No. }\end{array}$ & Waves frequency & Vertical movements & $\begin{array}{c}\text { Angular } \\
\text { movements }\end{array}$ \\
\hline 1 & $R A O_{z}\left[(\mathrm{~m} / \mathrm{m})^{2}\right]$ & $R A O_{\theta}\left[(\text { grade } / \mathrm{m})^{2}\right]$ \\
\hline 2 & 0.074 & $0.171 \times 10^{-6}$ & 0.453 \\
\hline 3 & 0.088 & $1.129 \times 10^{-6}$ & 1.295 \\
\hline 4 & 0.104 & $2.577 \times 10^{-6}$ & 1.532 \\
\hline 5 & 0.105 & $1.686 \times 10^{-6}$ & 0.341 \\
\hline 6 & 0.128 & $0.635 \times 10^{-6}$ & 0.117 \\
\hline
\end{tabular}


RAO solves a set of linear algebraic equations to obtain the harmonic response of the body to regular waves. Ansys results for RAO z values as tridimensional chart are presented below. (Figure9)

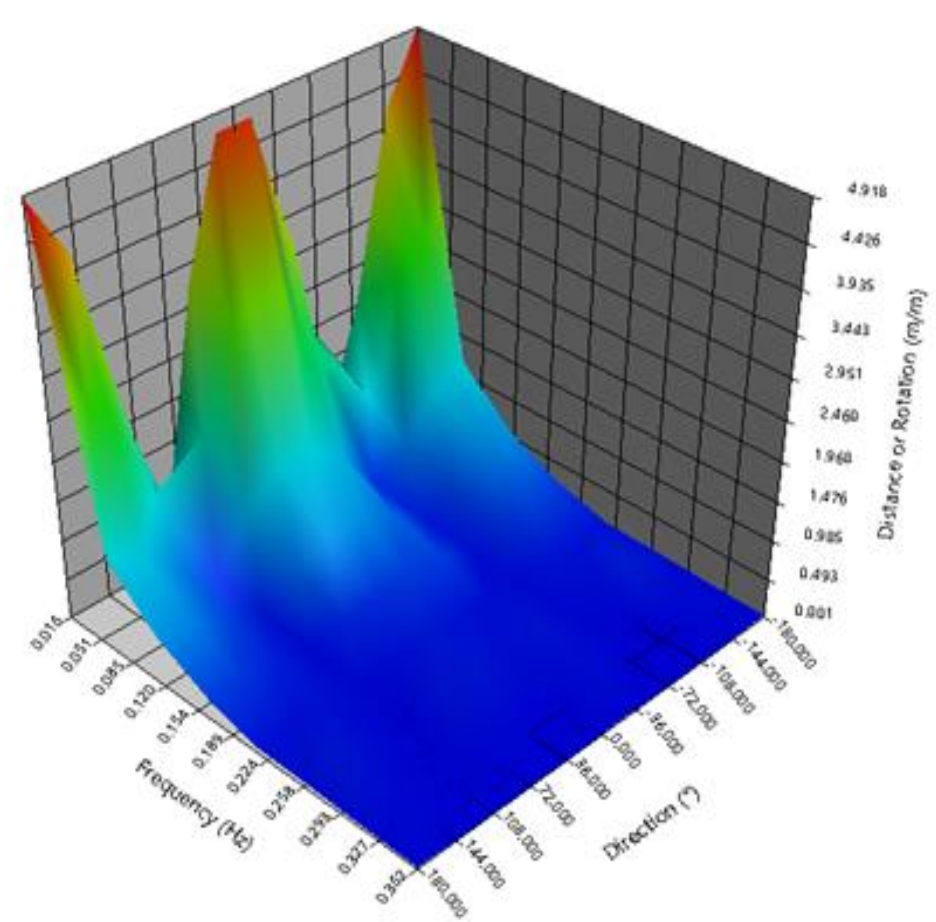

Figure 9.Computed RAOzresults for WindFloat (Distance versus Frequency and Direction)

Based on the Jonswapspectrum, wedetermine the response of the WindFloat structure by transforming each component of the spectrum into response and then by overlapping the results. The structure's response obtained is presented in Figure 10.

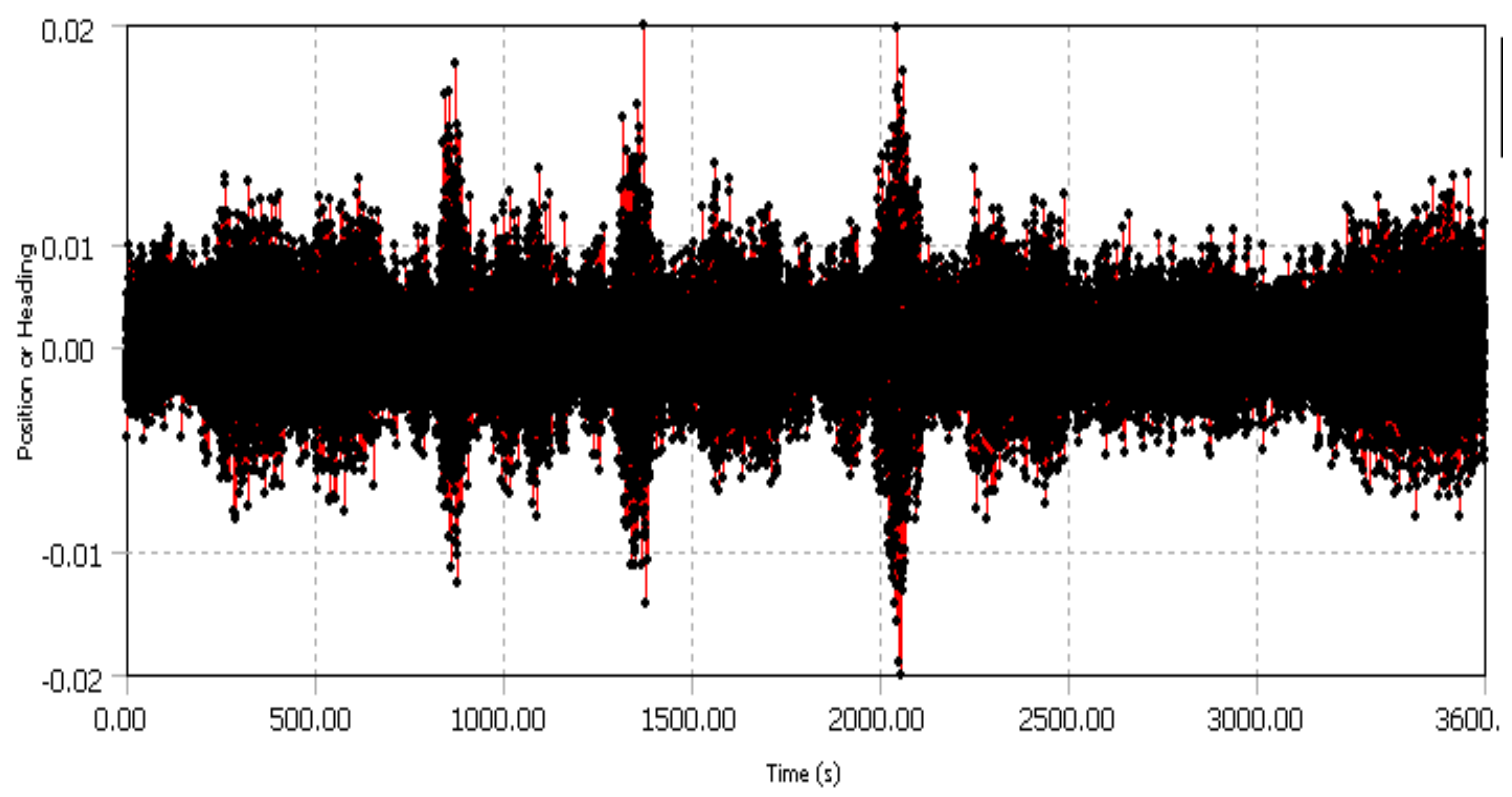

Figure 10.WindFloat response in the RAO-based Z-direction for JonswapHs $=1.2 \mathrm{~m} \mathrm{t}=3600 \mathrm{sec}$ 


\section{Conclusions}

The response amplitude operators (RAOs) show good sea keeping properties and low vertical movements. The response amplitude operators (RAOs) results of WindFloat structure are Ansysdetermined in 3D graph related to frequency and hydrodynamic interaction direction. With determined values of RAO function, the WindFloat structure is able to face all environmental hydrodynamic loads.

The RAO analyses show that the monitored floating structure is within the limits accepted by the ABS and respect structural integrity. However, aggregating all the results presented can have a significant impact on the design of future semi-submersibles.RAO numerical approach was designed in accordance marine loads and the I.T.T.C. recommendations.

The response of the semi-submersible structure is computed for each component of the Jonswap spectrum into response and after overlapping results we get the structure's response. WindFloat response in the RAO-based Z-direction for Jonswap Hs $=1.2 \mathrm{~m} \mathrm{t}=3600 \mathrm{sec}$ is a practical finding as graph of movements in time. The real dynamic response of offshore floating structures results from Ansys numerical simulation. This project of the Romanian Ministry of Defence, led to important conclusions by demonstrating usability of the RAO functions as relation between loads and vertical motion of semi-submersibles. The work opens the way for further hydrodynamic development for 3D RAO and hydrodynamic response of the WindFloat.

Author Contributions: The main ideas of this work and the first draft of the text belong to Ionut Cristian Scurtu. Delia Gârleanu participated in performing Ansys numerical simulations, describing marine loads and writing final article. Gabriel Gârleanu suggested improvements in Ansys simulation results presentation as 3D RAO and performed verification of the text and of the Figures. All authors agreed with the final form of this article.

Acknowledgement: This work was supported by the Romanian Ministry of Defence, grant PSCD 152/2018.

Conflicts of Interest: The authors declare no conflict of interest.

\section{References}

1. American Petroleum Institute (API) (2000), Planning, Designing and Constructing Fixed Offshore Platforms - Working Stress Design, API RP2A-WSD, 21st Edition.

2. American Petroleum Institute (API) (2005), Design and Analysis of Station keeping Systems for Floating Structures, API RP2SK, 3rd Edition.

3. Aranha, J.A.P. and Martins, M.R. (1997), 'Slender body approximation for yaw velocity terms in the wave drift damping matrix', Proceedings of 12th Int. Workshop on Water Waves and Floating Bodies, Marseilles, France.

4. Barltrop, N.D.P. (1998), Floating Structures: a guide for design and analysis, Vol. 1, CMPT and OPL.

5. Barltrop, N.D.P. and Adams, A.J. (1991), Dynamics of Fixed Marine Structures, 3rd Edition, ButterworthHeinemann Ltd, ISBN: 0750610468

6. Borgman, L.E. (1967), 'Random hydrodynamic forces on objects', the Annals of Mathematical Statistics, Vol.38, No.1, pp37-51. 
7. Faltinsen, O.M. (1990), Sea Loads on Ships and Offshore Structures, Cambridge University Press, ISBN: 0521458706 .

8. Chen, X.B. (2006), 'The set-down in the second-order Stokes' waves', Seventh International Conference on Hydrodynamics, 4-6 Oct. 2006. The Island of ISCHIA, Italy, ICHD 2006.

9. Kim, S., Sclavounos, P.D. and Nielsen, F.G. (1997), 'Slow-drift responses of moored platforms', the 8th BOSS Conference, Delft University of Technology, The Netherlands, 7-10 July 1997.

10. Ganea, D., Amortila, V., Mereuta, E., Rusu, E., A joint evaluation of the wind and wave energy resources close to the Greek Islands, (2017) Sustainability (Switzerland), 9 (6), art. no. 1025, . DOI: 10.3390/su9061025

11. Houmb, O.G. and Overvik, T. (1976), 'Parameterization of wave spectra', Proceeding of the first Conference on Behaviors of Offshore Structures (BOSS' 76), Trondheim, Norway, Vol. 1, pp.144-169.

12. Inglis, R.B., Price, W.G. (1981), 'A three dimensional ship motion theory-comparison between theoretical predictions and experimental data of the hydrodynamic coefficients with forward speed', Trans. RINA, Vol. 124, pp.141-157.

13. ITTC (2011), 'ITTC Recommended Procedures 7.5-02-07-04.5 - Numerical estimation of roll damping'

14. Kawahara, Y., Maekawa, K., Ikeda, Y. (2009), 'A simple prediction formula of roll damping of conventional cargo ships on the basis of Ikeda's method and its limitation', Proceedings of the 10th International Conference on Stability of Ships and Ocean Vessels (STAB2009), St. Petersburg, Russia.

15. Kim, Y. and Sclavounos, P.D. (1998), 'A finite-depth unified theory for linear and second-order problem of slender ships', Journal of Ship Research, Vol.2, No. 4, pp.297-309.

16. http://research.dnv.com/hci/ocean/bk/c/a28/s3.htm accesed onlin 10.08. 2018.

17. Cummins, W.E. (1962), 'The impulse response function and ship motions', Technical Report 1661, David Taylor Model Basin - DTNSRDC, 1962.

18. Du, S.X., Hudson, D.A., Price, W.G. and Temarel, P. (2009), 'Implicit expressions of static and incident wave pressures over the instantaneous wetted surface of ships', Proceedings of the Institution of Mechanical Engineers Part M: Journal of Engineering for the Maritime Environment, Vol. 223, No. 3, pp.239-256.

19. Dumitru, D. Numerical investigation of a two - Degrees - of - Freedom ship model for pitch - Roll motion (2016) IOP Conference Series: Materials Science and Engineering, 145 (8), art. no. 082007, DOI: 10.1088/1757-899X/145/8/082007

20. Pinkster, J.A. (1980), 'Low frequency second order wave exciting forces on floating structures', PhD. Thesis, TU Delft

21. Niculescu, D.M., Rusu, E.V.C., Evaluation of the new coastal protection scheme at Mamaia Bay in the nearshore of the black sea, (2018) Ocean Systems Engineering, 8 (1), pp. 1-20,DOI: 10.12989/ose.2018.8.1.001

22. Ochi, M.K. and Shin, Y.S. (1988), 'Wind turbulent spectra for design consideration of offshore structures', Proceedings of Offshore Technology Conference, Houston, USA, Paper No. 5736, pp 461-467.

23. Ostergaard, N.H., Lyckegaard, A., and Andreasen, J.H. (2011), 'Simulation of frictional effects in models for calculation of the equilibrium state of flexible pipe armouring wires in compression and bending', Journal of Structural Mechanics, Vol. 44, No. 3, pp. 243-259.

24. Preda, A., Scupi, A.A., Energy review on a maritime energy transfer system for commercial use (2014) Advanced Materials Research, 837, pp. 763-768. DOI: 10.4028/www.scientific.net/AMR.837.763

25. Sabău, A. Comparison of two thermodynamic combustion models, (2018) IOP Conference Series: Earth and Environmental Science, 172 (1), art. no. 112033,DOI: 10.1088/1755-1315/172/1/012033 
26. Scupi, A.A. The use of numerical programs in research and academic institutions (2016) IOP Conference Series: Materials Science and Engineering, 145 (8), art. no. 082002, DOI: 10.1088/1757-899X/145/8/082002

27. Stan, L.C. Simulation of air pollution due to marine engines, (2017) IOP Conference Series: Materials Science and Engineering, 227 (1), art. no. 012121, DOI: 10.1088/1757-899X/227/1/012121

28. Stan, L.C., Călimanescu, I., Velcea, D.D., Design check of an S-Lay offshore pipeline launching using numerical methods, 2016) IOP Conference Series: Materials Science and Engineering, 145 (8), art. no. 082017, DOI: 10.1088/1757-899X/145/8/082017

29. Stan, L.-C., Calimanescu, I. Computer fluid dynamics (CFD) study of a plate heat exchanger working with nanofluids (2016) Proceedings of SPIE - The International Society for Optical Engineering, 10010, art. no. 1001021, . DOI: $10.1117 / 12.2241677$

30. Randall, R.E. (1997), Element of Ocean Engineering, Society of Naval Architects and Marine Engineers, ISBN: 0939773244.

31. Rawson, K.J. and Tupper, E.C. (1984), Basic Ship Theory, Third edition, Longman Group Limited, ISBN: 0582305276 .

32. Robinson, R.W. and Stoddart, A.W. (1987), 'An engineering assessment of the role of non-linearities in transportation barge roll response', Transactions of Royal Institution of Naval Architects, pp.65-79

33. Raicu, A., Oanta, E., Sabau, A. Making objective decisions in mechanical engineering problems(2017) IOP Conference Series: Materials Science and Engineering, 227 (1), art. no. 012108,DOI: 10.1088/1757899X/227/1/012108

34. Rainey, R.C.T (1995), 'Slender-body expressions for the wave load on offshore structures', Proc. R. Soc. London A, 450, pp. 391-416

35. K. P. Thiagarajan, A Review of Floating Platform Concepts for Offshore Wind Energy Generation, Journal of Offshore Mechanics and Arctic Engineering. [DOI: 10.1115/1.4026607]

36. Dominique Roddier, WindFloat: A floating foundation for offshore wind turbines, Journal of Renewable and Sustainable Energy, DOI: 10.1063/1.3435339

37. Christian Cermelli, WindFloat: A Floating Foundation for Offshore Wind Turbines-Part II: Hydrodynamics Analysis, ASME 2009 28th International Conference on Ocean, Offshore and Arctic Engineering, DOI: 10.1115/OMAE2009-79231.

38. Antoine Peiffer, Estimation of Onsite Wave Parameters From the WindFloat Platform, ASME 2013 32nd International Conference on Ocean, Offshore and Arctic Engineering, DOI: 10.1115/OMAE2013-10002.

39. Christian Cermelli, Implementation of a 2MW Floating Wind Turbine Prototype Offshore Portugal, Offshore Technology Conference 2012 DOI: 10.4043/23492-MS.

40. Antoine Peiffer, Dominique Roddier, Floating Wind Turbines: The New Wave in Offshore Wind Power, book: Alternative Energy and Shale Gas Encyclopedia DOI: 10.1002/9781119066354.ch6 